University of Massachusetts Amherst

ScholarWorks@UMass Amherst

Chemistry Department Faculty Publication Series

Chemistry

1995

\title{
The use of Nafion dryer tubes for moisture removal in flow injection chemical vapor generation atomic absorption spectrometry
}

NG Sundin

University of Massachusetts Amherst

Julian Tyson

University of Massachusetts Amherst

C P. Hanna

S A. McIntosh

Follow this and additional works at: https://scholarworks.umass.edu/chem_faculty_pubs

Part of the Chemistry Commons

\section{Recommended Citation}

Sundin, NG; Tyson, Julian; Hanna, C P.; and McIntosh, S A., "The use of Nafion dryer tubes for moisture removal in flow injection chemical vapor generation atomic absorption spectrometry" (1995). Spectrochimica Acta Part B. 1314.

Retrieved from https://scholarworks.umass.edu/chem_faculty_pubs/1314 


\title{
The use of Nafion dryer tubes for moisture removal in flow injection chemical vapor generation atomic absorption spectrometry
}

\author{
Nils G. Sundin and Julian F. Tyson $\dagger$ \\ Department of Chemistry, University of Massachusetts, Box 34510, Amherst, MA 01003-4510, U.S.A.
}

Christopher P. Hanna and Susan A. McIntosh

The Perkin-Elmer Corporation, 761 Main Avenue, Norwalk, CT 06859, U.S.A.

(Received 25 May 1994; accepted 17 October 1994)

\begin{abstract}
A significant problem with flow injection chemical vapor generation atomic absorption spectrometry is a loss of sensitivity and blockage of transfer lines due to excessive moisture transported to the atom cell or lodged in the transfer line. A Nafion dryer tube was used to remove moisture from the wet carrier gas stream. The hygroscopic Nafion membrane removed water at $1.7 \mathrm{mg} / \mathrm{min}$ at an efficiency of $95 \pm 4 \%$ when $\mathrm{SnCl}_{2}$ was used as the reductant. When $0.4 \%(\mathrm{~m} / \mathrm{v})$ borohydride was used as the reductant, $2.3 \mathrm{mg} / \mathrm{min}$ of water was removed at an efficiency of $91 \pm 3 \%$. No measurable change in precision was observed and a $5 \%$ reduction in peak height sensitivity (vs. PTFE) was seen for mercury when using the Nafion transfer line. At $60^{\circ} \mathrm{C}$ the Nafion dryer removed $4.9 \mathrm{mg} / \mathrm{min}$ of water vapor at an efficiency of $93 \pm 3 \%$. The loss of mercury vapor through the Nafion membrane was no more than $0.04 \%$. Only a $3 \%$ reduction in peak height sensitivity was observed for the determination of arsenic and selenium. Detection limits for mercury, calculated from calibration data, were $77 \mathrm{ppt}, 20 \mathrm{ppt}$ and $150 \mathrm{ppt}$ for the PTFE tube, the model MD-250 dryer and the model MD-125 dryer, respectively.
\end{abstract}

\section{INTRODUCTION}

Mercury and the metalloid elements ( $\mathrm{As}, \mathrm{Bi}, \mathrm{Sb}, \mathrm{Se}, \mathrm{Sn}, \mathrm{Te}$ ) are most often determined by chemical vapor generation atomic absorption spectrometry. This method involves the use of reagents, such as tin(II) chloride or sodium borohydride, to convert the aqueous analyte to a gaseous product. The resulting elemental mercury or metalloid hydride is then stripped from solution in a gas-liquid separator using an inert carrier gas and directed to an atomic absorption spectrometer. Typically, the atomizer is a heated T-shaped quartz cell aligned in the optical light path. Several workers have noted problems such as loss of sensitivity and even blockage of transfer lines due to excessive moisture transported to the atom cell or lodged in the transfer line [1-3]. Several methods have been used to prevent carryover of moisture from the gas-liquid separator into the atom cell, most of which involve a desiccant. A radioactive tracer study of anhydrous calcium chloride showed that no more $4 \%$ of the hydride was lost [4]. Concentrated sulfuric acid [5], dry ice and methanol [6], silica gel and magnesium perchlorate [7] have been used. All of these agents remove moisture from the system but need periodic replenishment. More serious problems with this approach are that contaminants from the desiccant can be introduced and also that the analyte can be lost through trapping and/or adsorption, especially when silica gel is used.

Recently, CoRNS et al. [8] showed that the incorporation of a Nafion drying tube between the gas-liquid separator and the atom cell in a continuous-flow atomic fluorescence system for the determination of mercury improved the long term stability and enhanced the sensitivity. Both of these effects were attributed to the continuous removal of water vapor. Similar effects were claimed by AIZPUN FERNANDEZ et al. [9] in the determination of mercury by both atomic absorption and atomic emission

$\dagger$ Author to whom correspondence should be addressed. 


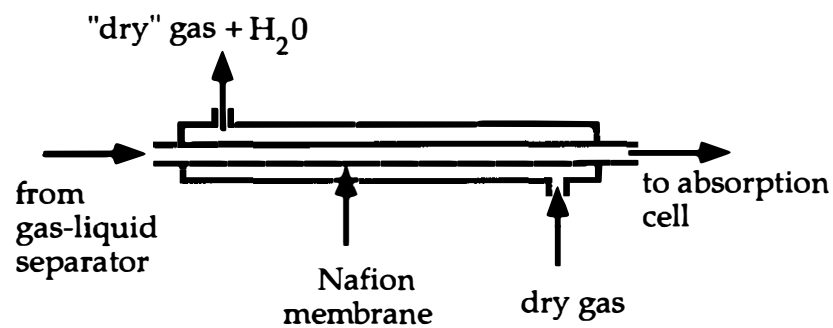

Fig. 1. Cross section of the Nafion dryer tube indicating the drying principle.

spectrometry procedures in which mercury vapor was generated by borohydride reduction from organized media and separated from the liquid phase by a grid nebulizer. CoRns et al. [10] have also described a hydride generation atomic fluorescence system for the determination of arsenic and selenium, in which a Nafion dryer tube was incorporated into the gas transfer line. The role of the dryer was not studied.

Nafion is a polymer similar to Teflon except that a sulfonic acid group is added to the chain giving the material a high affinity for water such that up to 13 molecules of water can be absorbed for every sulfonic acid group. Thus Nafion can absorb up to $22 \%$ of its weight in water. In addition, its Teflon backbone structure makes it very resistant to degradation from acids.

The dryer consists of a hollow tube of Nafion surrounded by a dry purge gas flowing in a coaxial sheath around the Nafion. When the carrier gas containing water vapor passes through the inside of the hollow tube, the water is absorbed by the Nafion material and moves through the walls of the material. If the dry sheath gas is passed over the exterior of the Nafion, water is continuously removed until the humidity of the carrier gas stream matches that of the purge gas. A cross section showing the operation of the Nafion dryer is shown in Fig. 1. The water removal process is driven by the humidity gradient between the interior and the exterior of the gas stream.

The aim of this work was to quantify the performance of the Nafion dryer in terms of moisture removal characteristics and to study the effect of the device on the sensitivities and precisions of the systems for the determination of mercury, arsenic and selenium.

\section{EXPERIMENTAL}

\subsection{Instrumentation}

A Perkin-Elmer FIAS 200 flow injection system was used. The system consisted of two peristaltic pumps, flexible pump tubing, PTFE connecting tubing $(0.7 \mathrm{~mm}$ i.d.), injection valve, manifold connectors and a carrier gas flow regulator in a single housing. The timing of the valve, speed of the pumps, purge time, heating of the quartz atomizer, and data collection were all controlled through Perkin-Elmer GEM software supplied with the unit running on a Digital DECStation 316sx PC computer. This system was connected to a Perkin-Elmer 3100 atomic absorption spectrometer. The flow injection manifold used for this work is shown in Fig. 2 and the operating parameters are listed in Table 1. The argon carrier flow was optimized for the maximum signal for a $10 \mathrm{ppb}$ standard solution.

A Perkin-Elmer Amalgam System was also used in some experiments to trap mercury vapor onto a rolled piece of gold/platinum gauze. The unit controls a purge gas for the manifold and an argon carrier for the vaporized mercury and pressurized air cooling gas. The gauze consisted of a wire mesh, $1.2 \mathrm{~cm}$ long, inside a $15 \mathrm{~cm}$ quartz tube $(0.3 \mathrm{~cm}$ i.d.). Mercury is trapped onto the gauze when cooled and subsequently released by heating the gauze to approximately $600^{\circ} \mathrm{C}$ using two $10 \mathrm{~W}$ tungsten lamps.

Two models of Nafion dryer (Perma Pure, Toms River, NJ) were used in this study. 


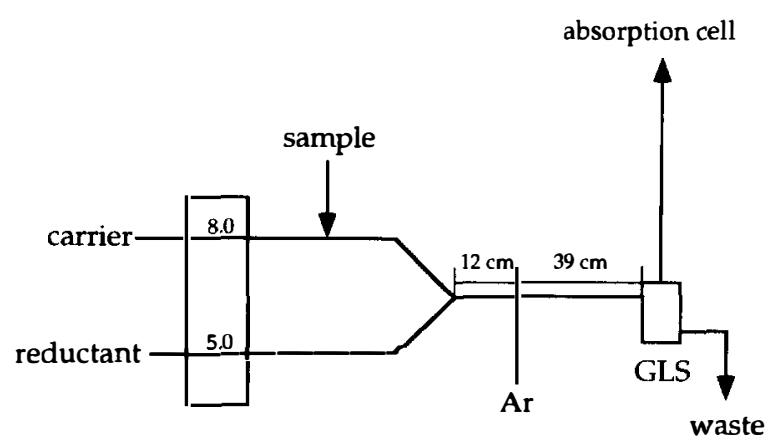

Fig. 2. Flow injection hydride-generation AAS manifold for the determination of mercury, arsenic or selenium. All manifold tubing is $0.7 \mathrm{~mm}$ i.d. GLS, gas-liquid separator; W, waste. Reagent flow rates are shown on the pump in $\mathrm{ml} / \mathrm{min}$.

Table 1. Instrument operating conditions

\begin{tabular}{ll}
\hline Parameter & Value \\
\hline Mercury hollow cathode lamp current & $6 \mathrm{~mA}$ \\
Mercury wavelength & $253.7 \mathrm{~nm}$ \\
Arsenic hollow cathode lamp current & $16 \mathrm{~mA}$ \\
Arsenic wavelength & $193.7 \mathrm{~nm}$ \\
Spectral bandpass for mercury and arsenic & $0.7 \mathrm{~nm}$ (reduced height) \\
Selenium electrodeless discharge lamp current & $280 \mathrm{~mA}$ \\
Selenium wavelength & $196.0 \mathrm{~nm}$ \\
Spectral bandpass for selenium & $0.2 \mathrm{~nm}$ (reduced height) \\
Quartz tube atomizer temperature & $200^{\circ} \mathrm{C}$ for Hg \\
Volume injected & $900^{\circ} \mathrm{C}$ for As and Se \\
Argon carrier flow & $500 \mu l$ \\
Dry argon sheath gas flow rate & $80 \mathrm{ml} / \mathrm{min}$ for Hg and As \\
\hline
\end{tabular}

Model MD-125 contained a Nafion membrane $30.5 \mathrm{~cm}$ long with an i.d. of $1 \mathrm{~mm}$. Model MD-250 was also $30.5 \mathrm{~cm}$ long but had an i.d. of $2.2 \mathrm{~mm}$.

Drierite drying tubes (Fisher) filled with a colored indicator and calcium sulfate were used to quantify the amount of moisture in various gas streams by gravimetry.

\subsection{Reagents}

All solutions were prepared with distilled, deionized water produced from a E-pure system (Barnstead). The mercury carrier stream solution was prepared by diluting ACS grade $\mathrm{HCl}(37 \% \mathrm{~mm}$, Fisher) to a concentration of $3 \%(\mathrm{v} / \mathrm{v})$ with distilled, deionized water. The carrier stream solution for both the arsenic and selenium studies was $10 \% \mathrm{HCl}(\mathrm{v} / \mathrm{v})$. Tin(II) chloride reducing agent solution $(1 \% \mathrm{~m} / \mathrm{v})$ was prepared by dissolving $10.0 \mathrm{~g}$ of tin(II) chloride dihydrate (Fisher) in $100 \mathrm{ml}$ of concentrated $\mathrm{HCl}$ and diluting to $1000 \mathrm{ml}$. Sodium borohydride solutions were prepared by dissolving $4.0 \mathrm{~g}$ of the powder in $1000 \mathrm{ml}$ of $0.05 \%$ sodium hydroxide (pellet form, Fisher) and then filtering through a Whatman No. 42 filter paper under suction. Standard solutions were prepared by dilution of $1000 \mathrm{mg} / \mathrm{l}$ stock solutions of $\mathrm{Hg}(\mathrm{II}) \mathrm{As}(\mathrm{V})$ or $\mathrm{Se}(\mathrm{VI})$ (Fisher). The mercury standards were preserved with $0.5 \%(\mathrm{v} / \mathrm{v})$ nitric acid and $0.005 \%$ $(\mathrm{m} / \mathrm{v})$ potassium dichromate. The tin(II) solutions were used to reduce mercury while the borohydride was used as the hydride transfer reagent for the arsenic and selenium studies.

Any experiments requiring $\mathbf{A s}(\mathrm{III})$ solutions were prepared by appropriate dilution of the $\operatorname{As}(\mathrm{V})$ standard and pre-reducing the $\mathrm{As}(\mathrm{V})$ to $\mathrm{As}(\mathrm{III})$ with $10 \mathrm{ml}$ of $10 \%$ 


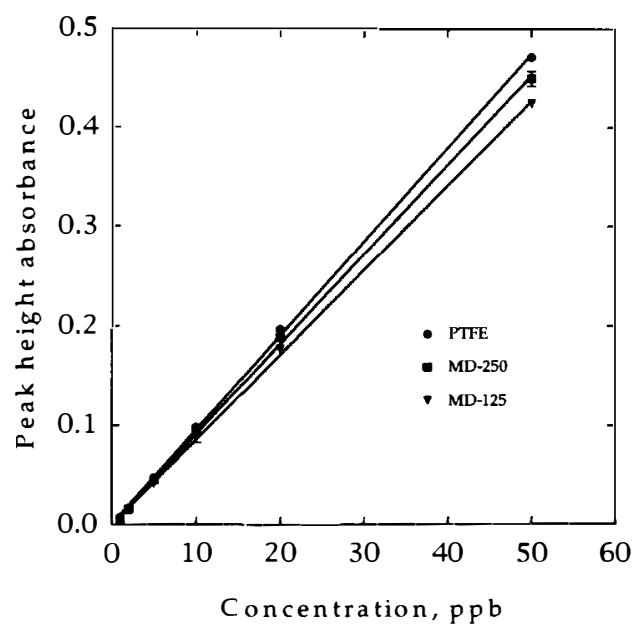

Fig. 3. Effect of type of transfer tubing on peak height sensitivity of mercury. See text for abbreviations.

$(\mathrm{m} / \mathrm{v})$ potassium iodide $/ 10 \%$ ascorbic acid with $10 \mathrm{ml}$ of concentrated hydrochloric acid for every $100 \mathrm{ml}$ of As(III) needed.

Experiments employing Se(IV) solutions were prepared by pre-reducing $500 \mu \mathrm{l}$ of a $1000 \mathrm{ppm} \mathrm{Se}(\mathrm{VI})$ standard in $80 \mathrm{ml}$ of $1: 1 \mathrm{HCl}$. Working standards were prepared by appropriate dilution of a $500 \mathrm{ppb}$ stock solution of Se(IV). The working standards also contained $10 \% \mathrm{HCl}(\mathrm{v} / \mathrm{v})$.

All standards and reductants were prepared fresh daily.

\subsection{Parameters studied}

The effect of the Nafion dryer on the following performance characteristics were investigated: (1) peak height sensitivity for mercury, arsenic and selenium; (2) rate of moisture removal for both ambient and elevated temperatures; (3) precision of repeated measurements; and (4) possible loss of analyte through the Nafion membrane.

\section{Results AND Discussion}

\subsection{Effects of Nafion dryer tubes on peak height sensitivity of mercury by flow injection atomic absorption spectrometry}

Initially, the two Nafion dryer tubes were compared with the standard $1 \mathrm{~mm}$ i.d. polytetrafluoroethylene (PTFE) transfer tubing on the basis of peak height sensitivity. Peak height absorbances were measured for six standards $(1,2,5,10,20$ and $50 \mathrm{ppb})$ as well as a blank for each of the three transfer lines for five replicate injections of $500 \mu$ l. The blank corrected peak height absorbance for each replicate was used to construct a calibration curve for each type of transfer tube. These are shown in Fig. 3. The PTFE calibration curve had a slope of $0.0095 \pm 0.0001 \mathrm{ppb}^{-1}$ (all quoted error values are $95 \%$ confidence intervals) while the MD-250 dryer gave a slope of $0.0090 \pm 0.0001 \mathrm{ppb}^{-1}$. The smaller dryer (MD-125) produced a calibration curve with a slope of $0.0085 \pm 0.0001 \mathrm{ppb}^{-1}$. All slopes were calculated by a first order linear regression procedure. Thus the Nafion transfer line produces a reduction in sensitivity of about $5 \%$ when compared with that of the PTFE transfer line. On the basis of visual inspection, all the calibration curves were linear up to $50 \mathrm{ppb}$. The MD-250 was used for future experiments as it gave the better sensitivity. Detection limits, calculated from the calibration data [11], were $77 \mathrm{ppt}, 20 \mathrm{ppt}$, and $150 \mathrm{ppt}$ for the PTFE tube, the model MD-250 dryer, and the model MD-125 dryer, respectively.

These results may be contrasted with those obtained by AizPUN Fernandez et al. [9] who found that the incorporation of the dryer tube improved the sensitivity of 
their atomic absorption determination by a factor of $20 \%$ to $0.007 \mathrm{ppb}^{-1}$. No reasons were proposed for this effect, and insufficient experimental details were given to allow further speculation.

\subsection{Effect of Nafion dryer tubes on precision by flow injection atomic} absorption spectrometry

For both the PTFE transfer line and MD-250, twenty one replicate injections of a $10 \mathrm{ppb}$ mercury standard were made. The percentage relative standard deviations were $1.0 \%$ for PTFE and $0.98 \%$ for MD-250. The values are not significantly different $(F$ test). For ten replicate determinations of a $50 \mathrm{ppb}$ solution Aizpun Fernandez et al. [9] reported relative standard deviation values of $2.5 \%$ and $1.9 \%$, for systems without and with the drier, respectively. These values are not significantly different. Similar results were reported by CoRNs et al. [8] for the short term atomic fluorescence determination but a considerable improvement in the precision after prolonged use was obtained when the Nafion dryer was used.

\subsection{Efficiency of water removal through the use of Nafion dryers}

For the study of water removal, water was pumped continuously in both channels for $2 \mathrm{~h}$. The wet argon carrier gas was directed through the Nafion dryer and then through a pre-weighed Drierite drying tube. The sheath gas flowing around the outside of the Nafion was directed to a separate pre-weighed Drierite tube. The MD-125 removed water at the rate of $1.25 \mathrm{mg} / \mathrm{min}$ while $\mathrm{MD}-250$ removed water at $1.71 \mathrm{mg} / \mathrm{min}$. The efficiency of water removal for MD-250 was determined to be $95 \pm 4 \%$.

To simulate the conditions when a large amount of water vapor is generated, as has been observed in certain kinds of flow injection manifolds [12], the reaction coil and gas liquid separator were heated to $60^{\circ} \mathrm{C}$ in a water bath. The Nafion dryer and Drierite were employed as described above to measure the amount of water removed by the dryer. Water vapor was removed at a rate of $4.9 \mathrm{mg} / \mathrm{min}$. Under these conditions water droplets were observed to form on the outside of the Nafion membrane. The efficiency was $93 \pm 3 \%$.

Similar experiments were also performed using an acid carrier stream and a borohydride reducing stream. These experiments were carried out in order to ensure that the performance of the Nafion dryer did not suffer when a more vigorous reaction took place. Solutions of $10 \% \mathrm{HCl}$ and $0.4 \%$ sodium borohydride were prepared as described in the experimental section. Again, the carrier gas and sheath gas were directed through Drierite drying tubes. The rate of water removal was $2.3 \mathrm{mg} / \mathrm{min}$ at an efficiency of $91 \pm 3 \%$.

The performance of the PTFE transfer line was variable. On some occasions water droplets would form immediately on starting an analysis and within minutes the quartz windows of the absorption cell would become fogged. On other occasions, 2-3 h of satisfactory operation would be obtained before the build up of water droplets and vapor became a problem.

\subsection{Effect of Nafion dryer on the recovery of mercury}

Two sets of experiments were performed in order to determine if any mercury was lost through the Nafion membrane which could account for the small reduction in peak height absorbance noted previously in Section 3.1.

3.4.1. Indirect measurement of mercury loss. The amalgam system was used to trap the mercury vapor from the transfer line. If no mercury is lost, then the same peak height and peak area should be measured for both the PTFE and the Nafion. Four replicate injections of $500 \mu \mathrm{l}$ were performed at each of six different mercury concentrations $(1,2,5,10,20$ and $50 \mathrm{ppb})$ and resulting mercury vapor was trapped onto the gold-platinum gauze and subsequently released through heating. The resulting peak heights and peak areas were measured. A two way analysis of variance (ANOVA) showed no statistically significant difference between either peak height or peak area when comparing PTFE with Nafion. Results are shown in Tables 2 and 3 for peak area and peak height, respectively. 
Table 2. Results of a two way ANOVA comparing PTFE and MD-250 using blank corrected peak area values

\begin{tabular}{lccccl}
\hline Source* & DF $\neq$ & Sum of squares & Mean square & $F$ & $p$ Value \\
\hline A & 1 & 0.001 & 0.001 & 0.923 & $p>0.25$ \\
B & 5 & 90.353 & 18.071 & 13228.4 & $p \leq 0.0001$ \\
A $\times$ B & 5 & 0.049 & 0.001 & 0.562 & $p>0.25$ \\
Error & 36 & 0.049 & 0.001 & & \\
Total & 47 & 90.407 & & & \\
\hline
\end{tabular}

* ' $A$ ' represents the two factors under comparison (PTFE and Nafion) and 'B' symbolizes the six concentration levels.

$\ddagger D F$ is number of degrees of freedom

Table 3. Results of a two way ANOVA comparing PTFE and MD-250 using blank corrected peak height values

\begin{tabular}{lccccl}
\hline Source* & DF $\ddagger$ & Sum of squares & Mean square & $F$ & $p$ Value \\
\hline $\mathrm{A}$ & 1 & $1.0 \times 10^{-6}$ & $1.0 \times 10^{-6}$ & 0.106 & $p>0.25$ \\
$\mathrm{~B}$ & 5 & 1.272 & 0.254 & 26535.5 & $p \leq 0.0001$ \\
$\mathrm{~A} \times \mathrm{B}$ & 5 & $3.4 \times 10^{-5}$ & $6.9 \times 10^{-6}$ & 0.716 & $p>0.25$ \\
Error & 36 & $3.5 \times 10^{-4}$ & $9.6 \times 10^{-6}$ & & \\
Total & 47 & 1.273 & & & \\
\hline
\end{tabular}

* ' $A$ ' represents the two factors under comparison (PTFE and Nafion) and 'B'symbolizes the six concentration levels.

$\ddagger D F$ is number of degrees of freedom.

These results indicate that no mercury was lost through the Nafion membrane (on the assumption that no mercury is lost through the PTFE transfer tube).

3.4.2. Direct measurement of mercury loss. In a separate experiment the sheath gas was directed to the amalgam unit to determine if mercury was transferred across the membrane. A continuous flow experiment was performed with $250 \mathrm{ml}$ of a $50 \mathrm{ppb} \mathrm{Hg}$ standard as "carrier" stream and $1 \% \mathrm{Sn}$ (II) as the reductant. The generated mercury vapor was directed to the fume hood while the sheath gas was passed over the gauze. The mercury collected on the gold-platinum gauze after $1 \mathrm{~h}$ was vaporized and the resulting signal was measured. The resulting signal (for both peak height and peak area) corresponded to between 2.5 and $5.0 \mathrm{ng}$ and thus no more than $0.04 \%$ of the mercury was lost through the Nafion membrane.

\subsection{Effect of Nafion dryer tube on peak height sensitivity of arsenic}

Five replicate injections of arsenic(III) standards were made at six different concentrations $(1,2,5,10,20,50 \mathrm{ppb})$ for both the PTFE tube and the Nafion tube. A $10 \% \mathrm{HCl}$ carrier stream was merged with a $0.4 \%$ borohydride solution. The resulting peak heights and peak areas were measured. A two way ANOVA calculation showed that there was a statistically significant difference, for both peak height and peak area, between the two transfer lines. The slopes of the peak area calibration curves were $0.079 \pm 0.004 \mathrm{~s} \mathrm{ppb}^{-1}$ and $0.075 \pm 0.004 \mathrm{~s} \mathrm{ppb}^{-1}$ for PTFE and Nafion, respectively.

The ANOVA indicates a difference between the two transfer lines while the $95 \%$ confidence intervals of the regression procedure overlap (indicating no statistical significance between the transfer lines). This is because the regression procedure fits the best straight line through the data and there is always some "error" in this process. That is, the $y$ residuals (the difference between the fitted line and the individual data points) indicates the lack of fit between a linear model and the data. ANOVA, however, simply calculates the total variance in a set of data and partitions this among the various factors (concentration, type of transfer line, inherent variability and 
interaction). It does not fit a model to a set of data nor does it adjust parameters to minimize differences between the model and the data.

The results may indicate that some of the arsine is lost through the Nafion membrane. However, as shown from the mercury studies, the reduction in sensitivity is not necessarily due to loss of analyte, but may instead be due to a gas phase dilution because the MD-250 has an internal diameter of $2.2 \mathrm{~mm}$ in comparison with an i.d. of $1 \mathrm{~mm}$ for PTFE. In addition, SINEMUS et al. [13] point out that a typical flow injection hydride generation peak has a half-width of several seconds and a tail extending for more than $20 \mathrm{~s}$. This means that a significant area under the absorption profile is measured under a relatively low signal-to-noise ratio making such a measurement less reliable.

\subsection{Effect of Nafion dryer tube on peak height sensitivity of selenium}

Five replicate injections of selenium(IV) standards were made at six different concentrations $(1,2,5,10,20,50 \mathrm{ppb})$ for both the PTFE tube and the Nafion tube. A $10 \% \mathrm{HCl}$ carrier stream was merged with a $0.2 \%$ borohydride reductant solution. A two way ANOVA calculation shows that there was a statistically significant difference between peak height results but not between the peak area results. The slopes of the peak area calibration curves were $0.059 \pm 0.003 \mathrm{ppb}^{-1}$ and $0.058 \pm 0.003 \mathrm{ppb}^{-1}$ for PTFE and Nafion, respectively. The peak height difference indicated by ANOVA may again be an indication of a gas phase dilution or a carrier gas flow rate variation. The slopes of the calibration curves and the peak area ANOVA data indicate no loss of $\mathrm{SeH}_{2}$ through the Nafion membrane.

\section{Conclusion}

Nafion dryer tubes remove moisture efficiently from a wet carrier gas stream in a flow injection hydride generation AAS system. In comparison with the use of chemical desiccants, use of a dryer tube has the advantages of avoiding (a) the introduction of contaminants and (b) significant analyte loss. In addition, there is no need for a shut down procedure to dry the system. The Nafion dryer removes over $90 \%$ of the moisture in the carrier gas both at room and elevated temperatures and does not adversely affect the performance characteristics of the hydride generation technique.

Acknowledgements-Financial support for this work from the Perkin-Elmer Corporation and many helpful discussions with Walter Slavin, Bonaire Technologies, are gratefully acknowledged.

\section{REFERENCES}

[1] R. C. Rooney, Analyst 101, 678 (1976).

[2] P. N. Vijan, A.C. Rayner, A. C. Sturgis and G. R. Wood, Anal. Chim. Acta 82, 329 (1976).

[3] G. Lindstedt, Analyst 95, 264 (1970).

[4] M. McDaniel, A. D. Shendrikar, K. D. Reiszner and P. W. West, Anal. Chem. 48, 2240 (1976).

[5] V. Cheam and H. Agemian, Anal. Chim. Acta 113, 237 (1980).

[6] F. Alt, J. Messerschmid and G. Tölg, Fresenius' Z. Anal. Chem. 327, 233 (1987).

[7] J. Piwonka, G. Kaiser and G. Tölg, Fresenius' Z. Anal. Chem. 321, 225 (1985).

[8] W.T. Corns, L. Ebdon, S. J. Hill and P. B. Stockwell, Analyst 117, 717 (1992).

[9] B. Aizpun Fernandez, M. R. Fernandez de la Campa and A. Sanz-Medel, J. Anal. At. Spectrom. 8, 1097 (1993).

[10] W. T. Corns, P. B. Stockwell, L. Ebdon and S. J. Hill, J. Anal. At. Spectrom. 8, 71 (1993).

[11] J. C. Miller and J. N. Miller, Statistics for Analytical Chemists, 3rd Edn., Ellis Horwood, Chichester, p. 117 (1993).

[12] C. P. Hanna, J. F. Tyson and S. McIntosh, Anal. Chem. 65, 653 (1993).

[13] H.-W. Sinemus, J. Kleiner, H.-H. Stabel and B. Radziuk, J. Anal. At. Spectrom. 7, 433 (1992). 